\title{
Simultaneous extraction of carotenoids and phenolic compounds from pulps of orange and yellow peach palm fruits (Bactris gasipaes) by ultrasound-assisted extraction
}

\author{
Sara Fonseca MONTEIRO ${ }^{1}$, Evellyn Laís Neves COSTA ${ }^{1}$, Ramon Sousa Barros FERREIRA², \\ Renan Campos CHISTÉ1,3* (D)
}

\begin{abstract}
Peach palm fruits (Bactris gasipaes) are native to the Amazonia and exhibit high levels of bioactive compounds, especially carotenoids and phenolic compounds. In our study, the ultrasound-assisted extraction (UAE) technique with different solvents [ethanol, ethyl acetate and ethanol/water $(1: 1, \mathrm{v} / \mathrm{v})$ ] was investigated to determine the best conditions for the simultaneous extraction of carotenoids and phenolic compounds from pulps of orange and yellow peach palm fruits to produce extracts with high bioactive compound contents. During the UAE experiments, the number of extraction and solid-liquid ratio were the variables that most affected bioactive compounds extraction $(p<0.05)$ and ethanol allowed the extraction of the highest carotenoid contents, while ethanol/water was the most efficient solvent to extract phenolic compounds. Through response surface methodology, ethanol/water resulted in optimal conditions at 10 extractions of $2 \mathrm{~min}$ each at a solid-liquid ratio of 1:12 (w/v) to extract phenolic compounds. Notwithstanding, the simultaneous extraction of carotenoids and phenolic compounds with ethanol and ethyl acetate was observed to be achieved at the same UAE conditions for both fruit varieties. Regardless the solvent, the UAE proved to be an efficient technique to carry out simultaneous extraction of high contents of carotenoids and phenolic compounds from pulps of peach palm fruits.
\end{abstract}

Keywords: Amazonian fruit; natural products; bioactive compounds; response surface methodology.

Practical Application: Carotenoids and phenolic compounds can be extracted from peach palm fruits to be used by food, cosmetic and pharmaceutical industries as bioactive ingredients.

\section{Introduction}

Peach palm (Bactris gasipaes Kunth) is native to the Amazon, which the varieties of ripe fruit vary according to the colour of the peel (green, light yellow, orange and red) (Silva \& Silva, 2016; Costa et al., 2019). In the Brazilian States covered by the Amazonian rainforest, peach palm fruits are mostly consumed after cooked in salty water, whereas they can be used as an ingredient in food formulations as raw material for the extraction of vegetable oils or for animal feed (Santos et al., 2017). The composition of peach palm fruits showed minerals, essential amino acids, proteins, vitamins and lipids, which makes them a food with high nutritional and sensorial properties and, in addition, they can be considered a promising source of bioactive compounds (Rojas-Garbanzo et al., 2011; Neri-Numa et al., 2018).

Among the bioactive compounds found in peach palm fruits, carotenoids and phenolic compounds are the most expressive and, according to the literature, the frequent intake of these compounds generally found in fruit and vegetables have been associated with a decrease in the incidence of chronic degenerative diseases (Luna-Guevara et al., 2018; Britton, 2020). Carotenoids are fat-soluble bioactive compounds with an extensive system of conjugated double bonds in their chemical structures, which confer high reactivity to the molecules, including light absorption in the visible range and antioxidant properties (Rodriguez-Amaya, 2019). Among the carotenoids reported in peach palm fruits, $\beta$-carotene is the major compound and plays an important role with high provitamin A activity and antioxidant action against free radicals and other reactive oxygen species, which are naturally generated during physiological processes by the human body (Jatunov et al., 2010). Phenolic compounds have diversified structures, consisting of molecules with low or high degree of polymerization that are based on aromatic rings with one or more hydroxyl substituents, which have the ability to donate hydrogen atoms or electrons to inhibit or delay oxidative processes in both food and physiological systems (Luna-Guevara et al., 2018). A recent study has reported that di-C-glycosyl flavones (schaftoside and vicenin-2) are the major phenolic compounds in peach palm fruits and these compounds are reported to exhibit various relevant biological activities (Chisté et al., 2021).

Carotenoids and phenolic compounds from fruit and vegetables are used by several industries, such as food, cosmetic 
and pharmaceutical, and the extraction of high levels of these compounds is mainly carried out by some classic solid-liquid extraction techniques (extraction by Soxhlet, maceration and hydrodistillation) (Wen et al., 2018; Manousi et al., 2019). The extraction efficiency by these classic techniques is commonly based on the use of different solvents with different polarities, application of heat and/or a mixture of both the factors (Azmir et al., 2013). However, such procedures are timeconsuming, need large amount of potentially toxic solvents to the environment and to the human body and they can induce degradation of the molecules due to the use of non-controlled heating (Cravotto et al., 2008).

Thus, considering these characteristics and aiming to minimize the impact of classical techniques, several unconventional and more ecological alternatives became more incident in the literature since they allowed the use of non-toxic solvents, presented short extraction time, low energy, solvent consumption and, in addition, they might exhibit higher yield and extract quality than the previous former techniques. Among the unconventional techniques, the ultrasound-assisted extraction (UAE) emerges as an alternative and efficient process to extract bioactive compounds from vegetable matrices (Chemat et al., 2019). During UAE process, the propagation of ultrasonic waves in the liquid medium induces a series of compression and rarefaction phases, which longitudinally displace the constituent molecules of the fluid, exerting a negative pressure in the medium and as constituent molecules are separated; they generate cavities in the liquid called cavitation bubbles. During cavitation phenomenon, the bubbles tend to oscillate and implode when they reach a critical value and when it happens close to the plant cell, some effects are observed, such as the reduction in the particle size of raw materials, rupture of the cell walls, and increased accessibility of solvents to raw material, among others (Chemat et al., 2017). According to Chemat et al. (2019), from these effects, several mechanisms were identified during UAE, such as fragmentation, erosion, sonocapillary effect, sonoporation, local shear stress and destruction-detexturation of plant structures; these mechanisms allow the extraction of compounds and may be responsible for increasing the extraction yield.

Even though the contents of phenolic compounds are much higher than carotenoids in peach palm fruits, the fruits are mostly known by their attractive colours due to the presence of carotenoids, and scientific information concerning phenolic compound contents are scarce (Rojas-Garbanzo et al., 2016, 2012). There are studies regarding classical solid-liquid extraction techniques of carotenoids and phenolic compounds from peach palm fruits (Basto et al., 2016; Rojas-Garbanzo et al., 2016; Matos et al., 2019). However, the application of UAE was investigated only for extracting total carotenoids from dried peels using vegetable oils (soybean and sunflower) (OrdóñezSantos et al., 2015; Ordoñez-Santos et al., 2019). As far as our knowledge is concerned, the application of UAE for the simultaneous extraction of carotenoids and phenolic compounds from the pulp of peach palm fruits with solvents with different polarities has not been reported yet. Therefore, the objective of this study was to investigate the better extraction conditions to obtain extracts with high levels of bioactive compounds from the pulp of peach palm fruits through UAE using different solvents to be used by any interested food, cosmetic and pharmaceutical industries.

\section{Material and methods}

\subsection{Peach palm fruits}

Two varieties of peach palm fruits (Bactris gasipaes Kunt) were acquired in November 2018 at a farmer trade fair located in Belém, Pará State, Brazil (latitude $01^{\circ} 27^{\prime} 21^{\prime \prime} S$ and longitude $\left.48^{\circ} 30^{\prime} 16^{\prime \prime} \mathrm{W}\right)$, based on the peel colour at ripe stage: orange and yellow (2 kg each) (Figure 1).

The access to the selected fruits was registered in the Brazilian National System for the Management of Genetic Heritage and Associated Traditional Knowledge (SisGen, ACC7773). The peach palm fruits were sanitized by immersion in a sodium hypochlorite solution $(100 \mu \mathrm{g} / \mathrm{mL})$ for $10 \mathrm{~min}$ before cooking

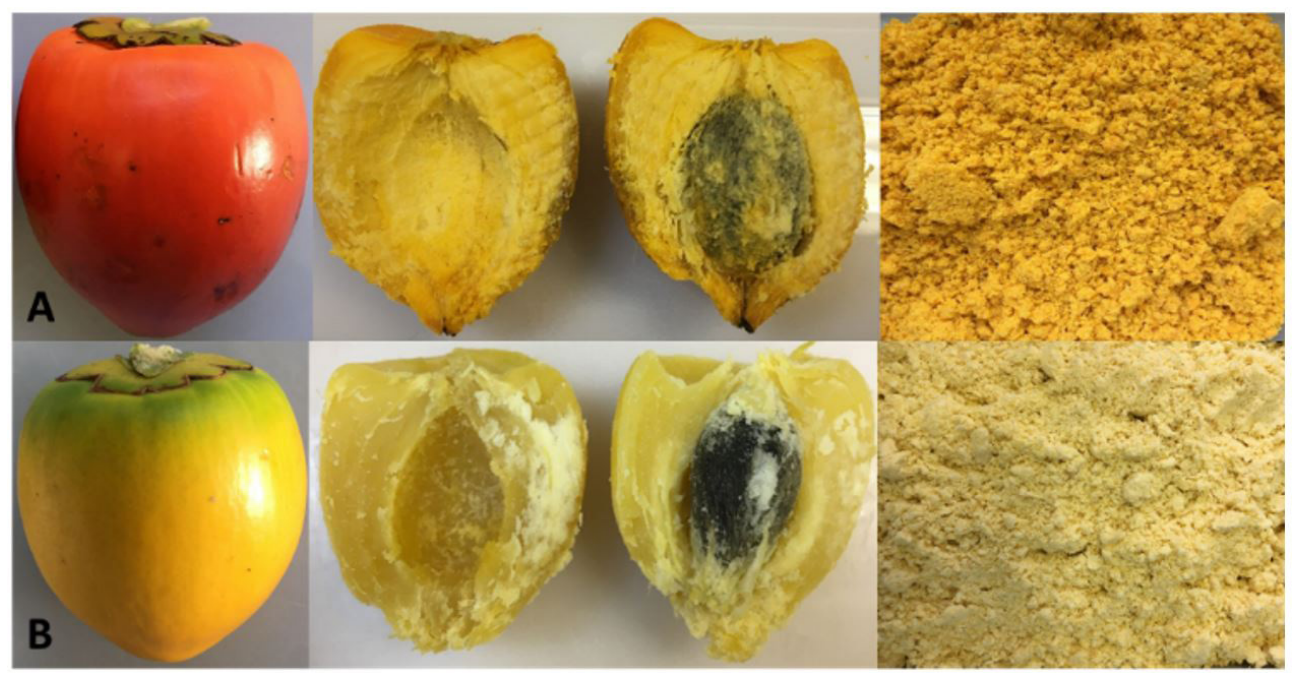

Figure 1. Peach palm fruits of the orange (A) and yellow (B) coloured peel varieties followed by the cooked fruits and the ground freeze-dried pulps. 
during 30 min under pressure in a pressure cooker, following the traditional procedure of Northern Brazil, and the pulps were manually separated from the peel and seed. The cooked pulps of the orange and yellow peach palm fruits were separated, freeze-dried (Liobras, model L101, São Paulo, Brazil), ground in a knife mill (Tecnal, model Willye TE-650, São Paulo, Brazil), vacuum-packed and stored protected from light at $-20^{\circ} \mathrm{C}$ until use.

\subsection{Determination of total carotenoids and phenolic compounds in the freeze-dried pulps}

\section{Total carotenoids}

The extraction of total carotenoids from the freeze-dried pulps $(2 \mathrm{~g})$ was carried out by a conventional method by exhaustive extraction with acetone in a mortar with pistil, at room temperature $\left(\approx 25^{\circ} \mathrm{C}\right)$, until the solid residue became colourless after successive vacuum-filtrations. The carotenoid extracts were submitted to liquid-liquid partition in diethyl ether/petroleum ether $(1: 1, \mathrm{v} / \mathrm{v})$, washed with distilled water, and after partition, the extracts were evaporated under vacuum $\left(\mathrm{T}<38^{\circ} \mathrm{C}\right)$ and re-solubilized in petroleum ether for spectrophotometric quantification at $450 \mathrm{~nm}$ (Rodriguez-Amaya, 2001). The total carotenoid contents $(n=3)$ were determined using the specific absorption coefficient of $\beta$-carotene in petroleum ether $\left(E_{1 \mathrm{~cm}}^{1 \%}=2592\right)$ (Davies, 1976) and expressed as $\mu \mathrm{g} / \mathrm{g}$ of freeze-dried pulps (dry basis, $\mathrm{db}$ ).

\section{Total phenolic compounds}

The total phenolic compound contents were determined by spectrophotometry, according to the colorimetric assay using the Folin-Ciocalteu reagent (Singleton et al., 1999). The phenolic compounds were exhaustively extracted following a conventional extraction procedure (Chisté et al., 2021), with adaptations. The freeze-dried pulps $(1 \mathrm{~g})$ with methanol/water solution $(80: 20, v / v)$, in a mortar with pistil, followed by vacuum-filtration, and the solid residue was submitted to the same extraction five times to combine the liquid extracts. The extractable total phenolic contents in the extracts were determined $(\mathrm{n}=3)$ at $760 \mathrm{~nm}$ by external nine-point analytical curves (in duplicate, $0.01-80 \mu \mathrm{g} / \mathrm{mL}$, $\left.r^{2}>0.99\right)$ and the results were expressed as $\mu$ g gallic acid equivalent (GAE)/g of freeze-dried pulps (dry basis, db).

\subsection{Ultrasound-Assisted Extraction (UAE) of carotenoids and phenolic compounds from peach palm pulps}

UAE conditions for the experimental design

The best conditions for the UAE of carotenoids and phenolic compounds from the freeze-dried pulps of both peach palm fruits (orange and yellow) were determined by the response surface methodology. A central composite rotational design (CCRD) was used with three independent variables at two levels $(-1,+1)$ : number of extraction (2-18 times), extraction time (2-12 $\mathrm{min})$ and solid-liquid ratio (1:4 - 1:14, w/v) (Table 1).

In our study, the solvents used in the UAE procedures were tested separately: ethanol, ethyl acetate and a mixture of ethanol/ water $(1: 1, \mathrm{v} / \mathrm{v})$, which were chosen considering the permissibility of residues in the extracts after evaporation, according to both Commission Directive 95/45/EC of the European Community (European Commission, 1995) and the US Food and Drug Administration (U.S Food and Drug Administration, 1997). The CCRD for each solvent and each type of freeze-dried peach palm pulp consisted of a $2^{3}$ factorial design plus 6 axial points and 4 repetitions at the central point totalizing 18 experiments (Table 2). The responses were total carotenoid and total phenolic compound contents.

\section{UAE procedure}

For all the experiments, the UAE of carotenoids and phenolic compounds were carried out in an ultrasonic bath (Eco-Sonics, model Q3.0 L, São Paulo, Brazil), at room temperature $\left(\approx 25^{\circ} \mathrm{C}\right)$, and fixed ultrasonic frequency at $25 \mathrm{KHz}$. The temperature was controlled with thermometer and ice addition to keep the room temperature. The freeze-dried pulp of each variety $(1 \mathrm{~g})$ was weighed in Erlenmeyers followed by the addition of the chosen solvent at variable solid-liquid ratios, and the flasks were placed into the ultrasonic bath during variable times and number of extractions, according to the parameters described in Table 1. After each selected time cycle, the liquid portion was removed from the Erlenmeyer and, after each number of extraction, they were combined to give a single extract containing carotenoids and phenolic compounds.

The extracts obtained by each solvent for each pulp variety were directed to the determination of total carotenoids and total phenolic compounds by spectrophotometry. Briefly, for total carotenoids, an aliquot of the ethanol extracts was directly measured at $450 \mathrm{~nm}$ and the contents were determined using the specific absorption coefficient of $\beta$-carotene in ethanol $\left(E_{1 \mathrm{~cm}}^{1 \%}=2620\right)($ Davies, 1976), while an aliquot of the ethyl acetate and ethanol/water extracts were evaporated under $\mathrm{N}_{2}$ flow and re-solubilized in petroleum ether to apply the specific absorption coefficient of $\beta$-carotene in petroleum ether. For total phenolic compounds, an aliquot of each extract was directly used in the colorimetric assay with Folin-Ciocalteu reagent by using the gallic acid analytical curves as external standard (Singleton et al., 1999). All the results were expressed as $\mu \mathrm{g} / \mathrm{g}$ of freeze-dried pulps.

Table 1. Levels of independent variables used in the central composite rotational design (CCRD) for the optimization of ultrasound-assisted extraction of carotenoids and phenolic compounds from peach palm pulps.

\begin{tabular}{ccccccc}
\hline \multirow{2}{*}{ Independent variable } & & \multicolumn{3}{c}{ Level } \\
\cline { 3 - 6 } & & -1.68 & -1 & 0 & +1 & +1.68 \\
\hline Number of extraction & $\mathrm{X}_{1}$ & 2 & 5 & 10 & 15 & 18 \\
Extraction time (min) & $\mathrm{X}_{2}$ & 2 & 4 & 7 & 10 & 12 \\
Solid-liquid ratio $(1: \mathrm{X}, \mathrm{w} / \mathrm{v})$ & $\mathrm{X}_{3}$ & 4 & 6 & 9 & 12 & 14 \\
\hline
\end{tabular}


Table 2. Contents of total carotenoids and phenolic compounds extracted from peach palm pulps of orange and yellow coloured fruit varieties during Central Composite Rotational Design (CCRD) by the ultrasound-assisted extraction technique.

\begin{tabular}{|c|c|c|c|c|c|c|c|c|c|c|c|c|c|c|c|}
\hline \multirow[b]{3}{*}{ Exp. } & \multirow{2}{*}{\multicolumn{3}{|c|}{ Levels of the independent variables }} & \multicolumn{6}{|c|}{ Total carotenoids $(\mu \mathrm{g} / \mathrm{g}$ of freeze-dried pulps)* } & \multicolumn{6}{|c|}{ Total phenolic compounds ( $\mu$ g GAE/g of freeze-dried pulps)* } \\
\hline & & & & \multicolumn{3}{|c|}{ Orange peach palm } & \multicolumn{3}{|c|}{ Yellow peach palm } & \multicolumn{3}{|c|}{ Orange peach palm } & \multicolumn{3}{|c|}{ Yellow peach palm } \\
\hline & 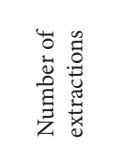 & 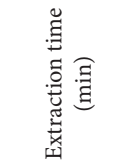 & 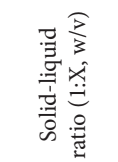 & 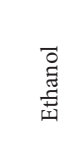 & 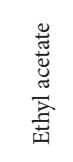 & 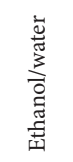 & 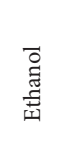 & 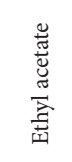 & 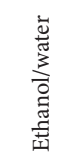 & $\begin{array}{l}\overrightarrow{0} \\
\text { 壱 } \\
\text { 壱 }\end{array}$ & 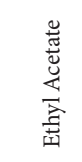 & 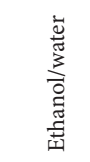 & $\begin{array}{l}\overrightarrow{0} \\
\text { 泀 } \\
\text { 吉 }\end{array}$ & 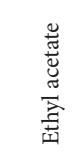 & 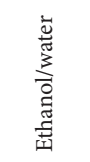 \\
\hline 1 & $5(-1)$ & $4(-1)$ & $6(-1)$ & 85.70 & 71.81 & 5.15 & 19.19 & 15.08 & 0.16 & 232.17 & 65.59 & 1536.57 & 69.82 & 16.10 & 1093.54 \\
\hline 2 & $15(+1)$ & $4(-1)$ & $6(-1)$ & 93.46 & 68.85 & 14.18 & 10.84 & 23.82 & 31.62 & 300.98 & 81.91 & 2054.85 & 7.35 & 67.75 & 1659.66 \\
\hline 3 & $5(-1)$ & $10(+1)$ & $6(-1)$ & 90.72 & 53.02 & 2.59 & 10.71 & 12.74 & 0.66 & 157.50 & 56.03 & 1390.46 & 45.95 & 14.82 & 1207.64 \\
\hline 4 & $15(+1)$ & $10(+1)$ & $6(-1)$ & 97.68 & 67.70 & 15.96 & 13.70 & 17.98 & 12.34 & 200.84 & 92.27 & 2165.67 & 93.90 & 55.13 & 1471.66 \\
\hline 5 & $5(-1)$ & $4(-1)$ & $12(+1)$ & 97.04 & 79.23 & 12.84 & 12.43 & 12.13 & 8.25 & 128.82 & 81.11 & 2042.47 & 488.44 & 62.72 & 1499.74 \\
\hline 6 & $15(+1)$ & $4(-1)$ & $12(+1)$ & 103.98 & 69.10 & 42.17 & 12.89 & 21.00 & 37.84 & 137.44 & 101.57 & 2492.49 & 115.10 & 69.65 & 1589.06 \\
\hline 7 & $5(-1)$ & $10(+1)$ & $12(+1)$ & 97.86 & 65.90 & 6.95 & 13.25 & 16.12 & 4.19 & 175.44 & 83.54 & 2082.13 & 46.57 & 72.49 & 1258.37 \\
\hline 8 & $15(+1)$ & $10(+1)$ & $12(+1)$ & 105.39 & 74.34 & 43.98 & 13.89 & 30.25 & 42.65 & 242.66 & 170.19 & 2569.43 & 478.54 & 130.47 & 1961.78 \\
\hline 9 & $2(-1.68)$ & $7(0)$ & $9(0)$ & 94.04 & 40.63 & 0.57 & 11.34 & 14.40 & 0.30 & 94.60 & 46.87 & 1248.66 & 156.90 & 21.46 & 836.99 \\
\hline 10 & $18(+1.68)$ & $7(0)$ & $9(0)$ & 104.97 & 63.73 & 35.51 & 15.16 & 25.55 & 32.87 & 128.00 & 242.25 & 2223.65 & 82.97 & 104.03 & 1858.61 \\
\hline 11 & $10(0)$ & $2(-1.68)$ & $9(0)$ & 97.70 & 73.06 & 23.05 & 13.78 & 18.25 & 24.25 & 234.34 & 169.68 & 2160.99 & 176.95 & 45.62 & 1547.31 \\
\hline 12 & $10(0)$ & $12(+1.68)$ & $9(0)$ & 95.99 & 26.69 & 18.25 & 12.31 & 13.99 & 12.22 & 249.58 & 163.24 & 2180.05 & 185.48 & 89.60 & 1672.12 \\
\hline 13 & $10(0)$ & $7(0)$ & $4(-1.68)$ & 91.85 & 44.52 & 5.08 & 17.78 & 16.82 & 4.36 & 210.90 & 80.98 & 1642.30 & 102.86 & 139.32 & 1326.38 \\
\hline 14 & $10(0)$ & $7(0)$ & $14(+1.68)$ & 95.96 & 47.66 & 41.46 & 14.70 & 13.23 & 31.27 & 459.10 & 172.82 & 2189.71 & 351.49 & 125.20 & 1657.94 \\
\hline 15 & $10(0)$ & $7(0)$ & $9(0)$ & 102.18 & 52.13 & 21.00 & 15.41 & 12.63 & 11.83 & 364.88 & 128.58 & 2094.51 & 344.17 & 86.14 & 1658.75 \\
\hline 16 & $10(0)$ & $7(0)$ & $9(0)$ & 101.11 & 50.09 & 21.17 & 13.60 & 8.43 & 13.60 & 394.82 & 109.20 & 2019.29 & 342.98 & 91.38 & 1542.89 \\
\hline 17 & $10(0)$ & $7(0)$ & $9(0)$ & 97.47 & 50.50 & 16.73 & 15.22 & 10.92 & 11.48 & 378.03 & 125.50 & 1884.00 & 343.35 & 83.26 & 1441.87 \\
\hline 18 & $10(0)$ & $7(0)$ & $9(0)$ & 97.61 & 51.24 & 15.04 & 12.65 & 10.89 & 13.03 & 497.41 & 115.46 & 2258.52 & 343.93 & 91.04 & 1482.76 \\
\hline
\end{tabular}

Exp. $=$ Experiment; $\mathrm{GAE}=$ gallic acid equivalent; ${ }^{*}$ Dry basis.

\section{Statistical analysis}

The results of the experimental design were analysed using the Statistica ${ }^{\circledR} 8.0$ software (Statsoft Inc.) using the response surface methodology (RSM) and all experimental data obtained by the CCRD were fitted to second order polynomial models. In addition, Pareto charts were built at $5 \%$ of statistical significance $(p \leq 0.05)$ to investigate the effect of the studied UAE conditions to extract carotenoids and phenolic compounds. The adequacy to the second order models was determined by evaluating the coefficient determination $\left(\mathrm{R}^{2}\right)$, lack of fit and Fisher test values (F-value) through Analysis of Variance (ANOVA) at 5\% of statistical significance $(\alpha=0.05)$. The mathematical models were considered significant $(\mathrm{p} \leq 0.05)$ when the regression $\mathrm{F}_{\text {values }}$ were three times higher than $\mathrm{F}_{\text {tabulated }}$ and as predictive when the lack of fit $\mathrm{F}_{\text {values }}$ were lower than the $\mathrm{F}_{\text {tabulated }}$ values (Box et al., 1978). The obtained mathematical models were used to generate response surfaces and contour plots to provide the UAE conditions for each solvent (ethanol, ethyl acetate and ethanol/water) that allows the simultaneous extraction of high levels of carotenoids and phenolic compounds. In the cases where the mathematical models were considered predictive and significant $(\alpha=0.05)$, the optimized conditions were experimentally verified (validation, in triplicate) in order to compare the predicted and experimental values to check the reliability of the predictive models.

\section{Results and discussion}

\subsection{Effects of the selected UAE conditions to extract carotenoids from peach palm pulps}

By the application of the conventional methodology to determine total carotenoid contents, the freeze-dried pulp of orange peach palm fruits presented higher values $(143.43 \pm 5.68 \mu \mathrm{g} / \mathrm{g}, \mathrm{db})$ than the yellow variety $(13.04 \pm 1.25 \mu \mathrm{g} / \mathrm{g}, \mathrm{db})$. These values were similar to the range reported for raw pulps of peach palm fruits $(19-339 \mu \mathrm{g} / \mathrm{g}, \mathrm{db})$ from 21 different trees collected in the same region in Northern Brazil, with pulp colour varying from yellow to orange (Carvalho et al., 2013).

The influence of the selected UAE conditions on the extraction of carotenoids from peach palm pulps of orange and yellow coloured fruit varieties during CCRD can be seen in Table 2. For the pulp of orange peach palm fruits, the procedures with ethanol and ethyl acetate solvents resulted in very low variation [relative standard deviation $(\mathrm{RSD})=2.4 \%$ and $1.4 \%$, respectively] in the total carotenoid concentration at the CCRD central points, which indicated high repeatability of the extraction procedure, while ethanol/water exhibited higher values $(\mathrm{RSD}=16.6 \%)$. On the other hand, for the pulp of yellow peach palm fruits, the procedures with ethanol and ethanol/ water provided lower RSD values (9.3\% and 7.9\%, respectively) in the contents of total carotenoids at the CCRD central points than ethyl acetate $(16.1 \%)$. 
In general, ethanol can be highlighted as the solvent that extracted the highest levels of carotenoids from the freeze-dried pulps of both orange and yellow peach palm fruits with slight differences among the values in the experimental design. For the pulp of orange peach palm fruits and using ethanol as solvent, the highest content of carotenoid extracted by the UAE $(105.39 \mu \mathrm{g} / \mathrm{g}$, Exp. 8 ) accounted for $\approx 73 \%$ of the value found by the conventional methodology and was achieved after 15 extractions of $10 \mathrm{~min}$ each at a solid-liquid ratio of 1:12 (w/v). Meanwhile, for the pulp of yellow peach palm fruits, ethanol extracted the highest carotenoid content $(19.19 \mu \mathrm{g} / \mathrm{g}$, Exp. 1$)$ after 5 extractions of $4 \mathrm{~min}$ each at a solid-liquid ratio of 1:6 (w/v), which was 1.5 times superior to the value showed by the conventional method. Ethanol is a solvent with high permeability to cell matrixes and its high diffusion favours solid-liquid extraction processes, which may increase the extraction efficiency of bioactive compounds by UAE due to the cavitation phenomenon that causes rupture of the cell walls (Moreira et al., 2017; Hazli et al., 2019), and the pulp of yellow peach palm fruits seemed to be more susceptible to this process than the orange variety.

Ethanol has intermediate polarity, it is able to solubilize lipophilic compounds, such as carotenoids, and previous studies also reported that ethanol was more efficient than ethyl acetate and ethanol/water mixture to extract carotenoids from annatto seeds (Carvalho et al., 2013) and Caryocar villosum pulps (Chisté et al., 2011) by conventional solid-liquid extraction technique (maceration). In addition, pulps of orange and yellow peach palm fruits were reported to contain $\beta$-carotene as the major carotenoid ( $20 \%$ and $24 \%$, respectively), while lutein was found at high percentage only in the yellow variety (14\%) (Chisté et al., 2021), and these carotenoids have high affinity to apolar solvents, but also with medium polar solvents.

The Pareto charts that highlight the effects of the studied UAE conditions (number of extraction, extraction time and solid-liquid ratio) to extract carotenoids from the freeze-dried pulp of peach palm fruits are available as Supplementary Material (Supplementary Figure 1). According to the charts, when the UAE was carried out to extract carotenoids from pulps of orange peach palm fruits, the efficiency of ethanol and ethanol/water $(1: 1, \mathrm{v} / \mathrm{v})$ was mainly affected by the number of extraction and the solid-liquid ratio, at significant levels ( $p \leq 0.05)$, and both with positive values, which mean that the higher the number of extraction or the solid-liquid ratio the higher the carotenoid contents, as can be observed in Table 2. However, when ethyl acetate was used, all the independent variables and their interactions affected the UAE of carotenoids $(\mathrm{p} \leq 0.05)$. The extraction time was the most relevant variable, with negative values, which indicate that the highest total carotenoid contents were found as the extraction time decreased. For the UAE of carotenoids from the pulps of yellow peach palm fruits, the Pareto charts indicated that the number of extraction (at the positive levels) was the most relevant condition responsible for the highest carotenoid contents during the CCRD experiments $(\mathrm{p} \leq 0.05)$ when ethyl acetate and ethanol/water $(1: 1, \mathrm{v} / \mathrm{v})$ were used; whereas ethanol was more efficient for the positive levels of the interaction between the number of extraction and extraction time. The solid-liquid ratio and the extraction time seem to be relevant variables to extract carotenoids by UAE, as also observed during the UAE of carotenoids from dried peels of peach palm fruits using sunflower and soy oils (OrdoñezSantos et al., 2019; Ordóñez-Santos et al., 2015) and carotenoids (bixin) from annatto seeds (Chisté et al., 2011).

\subsection{Effects of the selected UAE conditions to extract phenolic compounds from peach palm pulps}

The freeze-dried pulp of orange peach palm fruits exhibited higher values of total phenolic compounds $(1340.28 \pm 36.50 \mu \mathrm{g}$ $\mathrm{GAE} / \mathrm{g}, \mathrm{db})$ than the pulp of the yellow variety $(1026.65 \pm 23.46 \mu \mathrm{g}$ $\mathrm{GAE} / \mathrm{g}, \mathrm{db}$ ), as determined by the conventional methodology. These contents were $>1.5$ times superior to the values reported for raw and cooked pulp of peach palm fruits (orange to red colours) harvested in Costa Rica (720 and $700 \mu \mathrm{g} \mathrm{GAE} / \mathrm{g}, \mathrm{db}$, respectively) (Rojas-Garbanzo et al., 2012).

According to the total phenolic compounds contents for each solvent at the CCRD central points (Table 2), the low RSD values indicate high repeatability of the UAE technique for both peach palm pulps of orange and yellow-coloured fruits. For the orange peach palm fruits, the use of ethyl acetate and ethanol/water presented lower RSD (7.5\% and 7.6\%, respectively) than ethanol (14.7\%), while for the pulp of yellow fruits fruits, ethanol provided lower RSD value $(0.16 \%)$ than ethyl acetate $(4.5 \%)$ and ethanol/water (6.2\%). Among the tested solvents, the mixture of ethanol/water allowed the extraction of the highest levels of phenolic compounds from both fruit varieties. Interestingly, ethanol/water extracted the highest total phenolic compound contents from the pulp of both orange $(2569 \mu \mathrm{g} \mathrm{GAE} / \mathrm{g})$ and yellow $(1961 \mu \mathrm{g} \mathrm{GAE} / \mathrm{g})$ peach palm fruits at the same UAE conditions: 15 extractions of $10 \mathrm{~min}$ each at a solid-liquid ratio of 1:12 (w/v). These values were almost 2 times higher than the values found for the freeze-dried pulp fruits by the conventional methodology. The addition of water to ethanol was reported to increase their extraction efficiency by the swelling of plant material, which increases the penetration of the organic solvent into the sample matrix that intensify the mass transfer by molecular diffusion (Ghitescu et al., 2015), which may be increased by the cavitation phenomenon of UAE.

Orange and yellow peach palm fruits present similar phenolic compounds composition, being schaftoside the major compound in yellow (45\%) and orange (32\%) varieties, in addition to vicenin-2, which was found at high percentage in the pulp of orange peach palm fruits (21\%) (Chisté et al., 2021). These compounds are diC-glycosyl flavones and they have high affinity to intermediate polar solvents, such as ethanol. The highest efficiency of UAE of phenolic compounds over conventional extraction techniques was also observed for other fruits, such as jussara (Euterpe edulis Mart.), blueberry and grapes (Carrera et al., 2012; Rocha et al., 2017).

According to the Pareto charts (Supplementary Figure 2), when the UAE was carried to extract phenolic compounds from pulps of orange peach palm fruits, the efficiency of all the tested solvents was mainly affected by the number of extraction ( $\mathrm{p} \leq 0.05)$. As an example, the UAE using ethanol and ethyl acetate provided the highest contents of phenolic compounds in their sequence of experiments at the same extraction time $(7 \mathrm{~min})$ and solid-liquid ratio $(1: 9, \mathrm{w} / \mathrm{v})$, but ethyl acetate needed 18 extractions against 10 for ethanol. Importantly, the lowest extraction of phenolic compounds 
by the UAE for all the tested solvents was observed when the lowest level of the number of extraction was used (Exp. 9). In addition to the number of extraction, the increase in the solid-liquid ratio values also affected positively the phenolic compounds extraction when ethyl acetate and ethanol/water were used $(\mathrm{p} \leq 0.05)$.

For the UAE of phenolic compounds from pulps of yellow peach palm fruits, the Pareto charts (Supplementary Figure 2) indicated different tendencies among the solvents. For ethanol, the solid-liquid ratio was the most relevant variable (positive values), followed by the linear interaction between the number of extraction and extraction time $(\mathrm{p} \leq 0.05)$. Thus, the extraction of phenolic compounds with ethanol seemed to increase as the solid-liquid ratio was tested at the highest values of CCRD as long as the number of extraction and extraction time were fixed at the same condition, which can be confirmed by comparing Exp. 5 and Exp.6, as well as Exp. 13 and 14 (Table 2). For ethyl acetate and ethanol/water, the number of extraction was the variable that most affect $(p \leq 0.05)$ the UAE procedure, followed by solid-liquid ratio, both at the highest values of CCRD.

\subsection{Best conditions for the simultaneous extraction of carotenoids and phenolic compounds from peach palm pulps}

After performing ANOVA ( $\mathrm{p} \leq 0.05)$ (Supplementary Tables 1 and 2), not all the proposed mathematical models were able to efficiently predict the contents of total carotenoids and phenolic compounds in order to allow the optimization of the UAE process. For the orange peach palm fruits, the proposed models for ethanol/water $(1: 1, \mathrm{v} / \mathrm{v})$ were the only significant and predictive and exhibited the highest $\mathrm{R}^{2}(>90 \%)$. Meanwhile, for the yellow peach palm fruits, none of the proposed mathematical models was considered efficient to predict the contents of carotenoids of phenolic compounds since they were not significant and predictive (Table 3 ).

According to the contour plots (Figure 2), the optimal conditions for the simultaneous extraction of high levels of both bioactive compounds from orange peach palm fruits using ethanol/water were proposed to be after 10 extraction of $2 \mathrm{~min}$ each at a solid-liquid ratio of 1:12 (w/v). For the validation purpose, these optimal UAE conditions were experimentally verified and the total carotenoids and phenolic compound contents were

Table 3. Proposed mathematical models to predict the contents of total carotenoids and phenolic compounds from the freeze-dried pulp of peach palm fruits by the application of ultrasound-assisted extraction using different solvents.

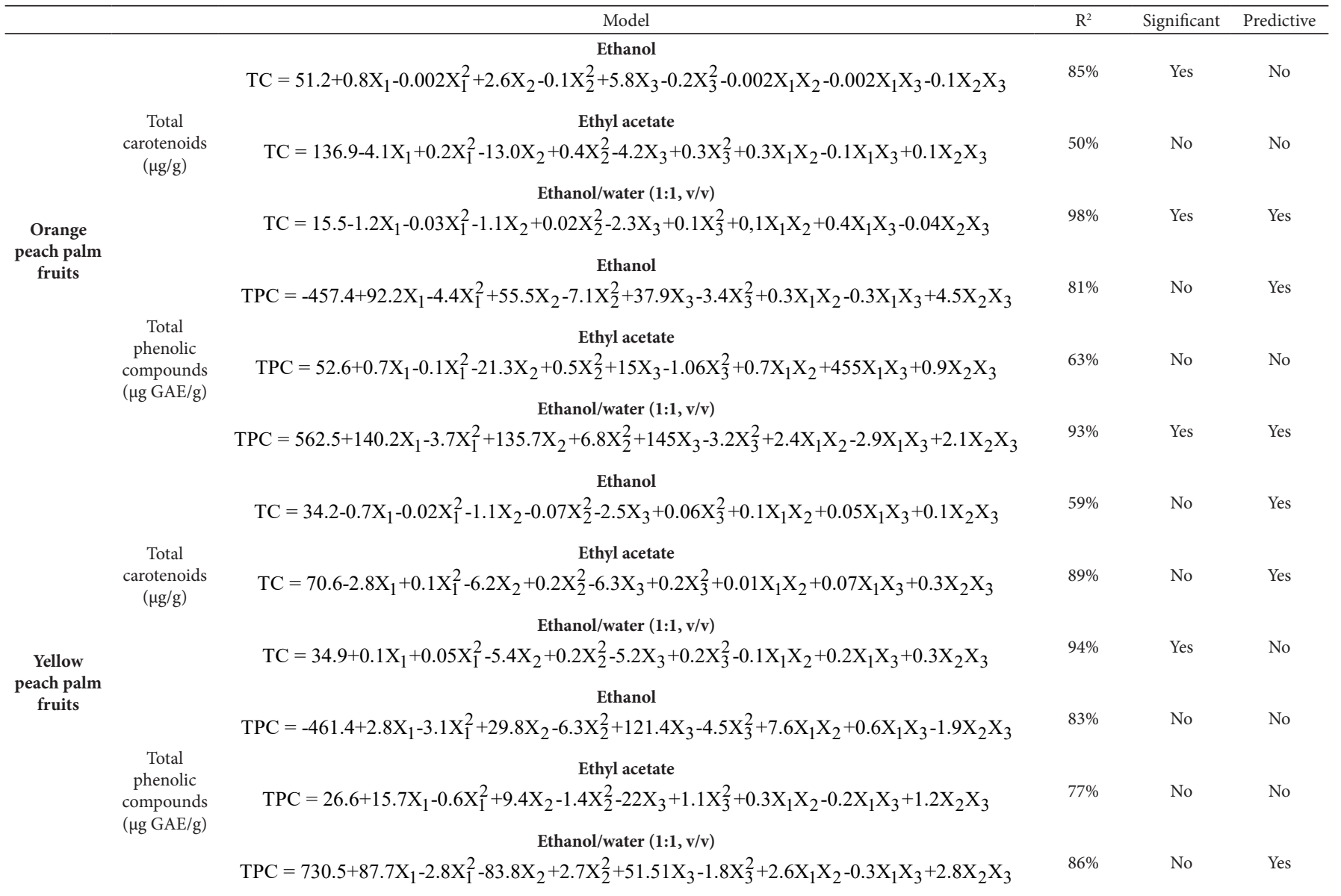

$\mathrm{TC}=$ total carotenoids; $\mathrm{TPC}=$ total phenolic compounds; $\mathrm{GAE}=$ gallic acid equivalent $\mathrm{R}^{2}=$ coefficient of determination; $\mathrm{X}_{1}=$ number of extraction; $\mathrm{X}_{2}=$ extraction time; $\mathrm{X}_{3}=$ solidliquid ratio $(1: \mathrm{X}, \mathrm{w} / \mathrm{v})$. The mathematical models were considered significant $(\mathrm{p} \leq 0.05)$ when the regression $\mathrm{F}_{\text {values }}$ were three times higher than $\mathrm{F}_{\text {tabulated }}$ and as predicted when the lack of fit $\mathrm{F}_{\text {values }}$ were lower than the $\mathrm{F}_{\text {tabulated }}$ value (Supplementary Tables 1 and 2). 

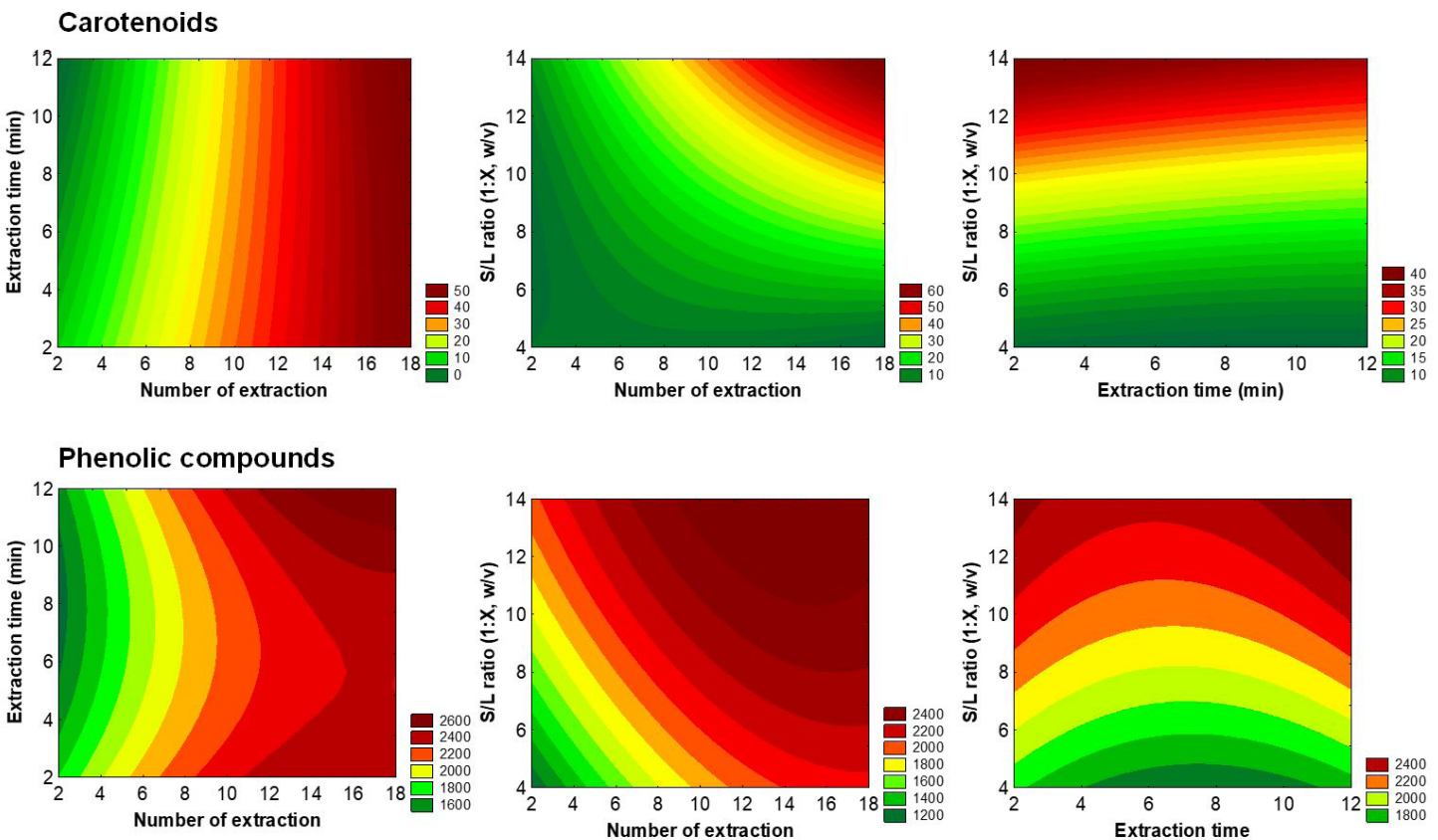

Figure 2. Contour plots used for the optimization of the simultaneous extraction of carotenoids $(\mu \mathrm{g} / \mathrm{g})$ and phenolic compounds ( $\mu \mathrm{g}$ gallic acid equivalent/g) from freeze-dried pulps of orange peach palm fruits by ultrasound-assisted extraction using ethanol/water (1:1, v/v).
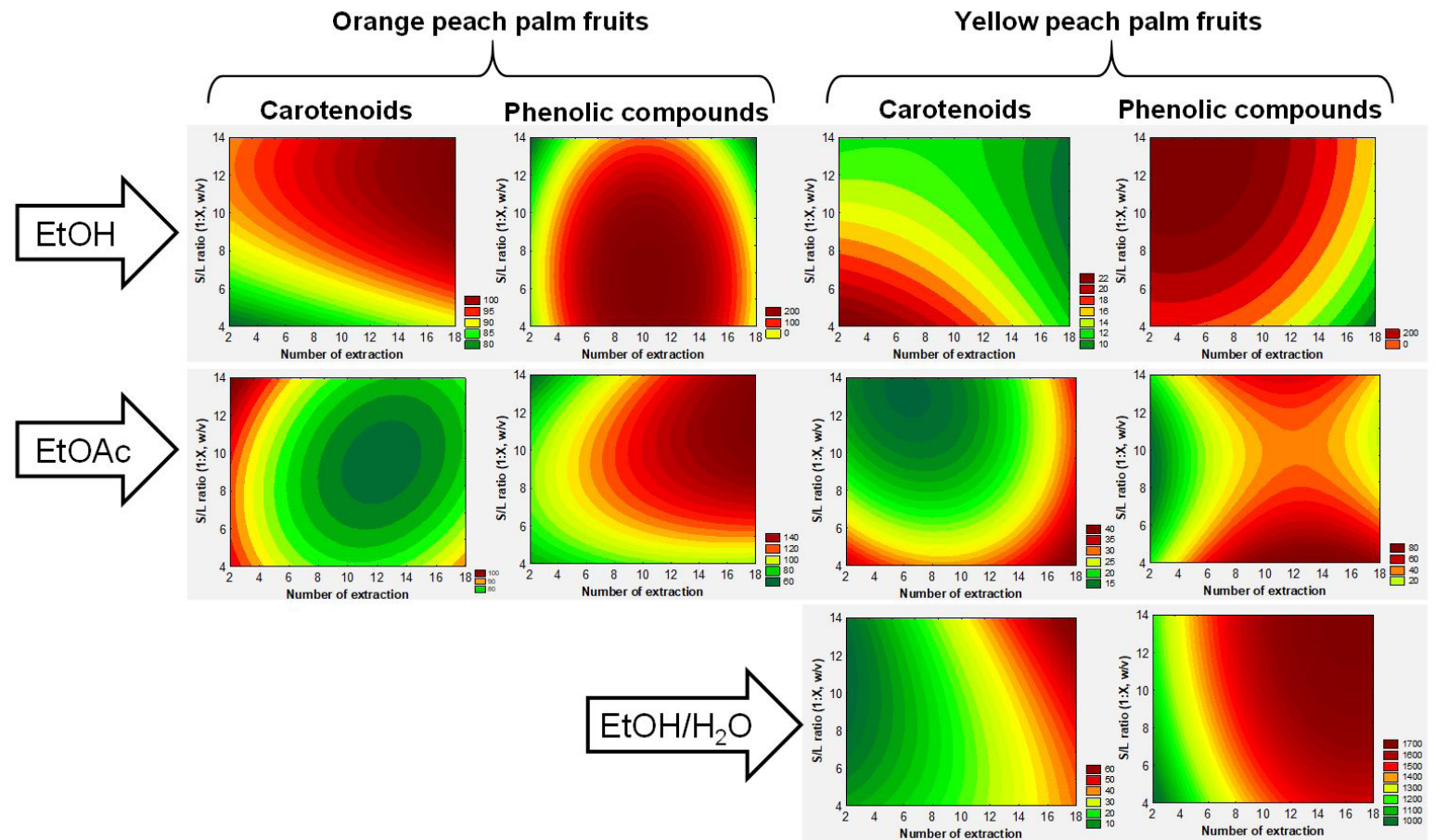

Figure 3. Contour plots built to illustrate the observed tendencies for the simultaneous extraction of carotenoids ( $\mu \mathrm{g} / \mathrm{g}$ ) and phenolic compounds ( $\mu \mathrm{g}$ gallic acid equivalent/g) from freeze-dried pulps of orange and yellow peach palm fruits by ultrasound-assisted extraction using ethanol $(\mathrm{EtOH})$, ethyl acetate $(\mathrm{EtOAc})$ and ethanol/water $(1: 1, \mathrm{v} / \mathrm{v})\left(\mathrm{EtOH} / \mathrm{H}_{2} \mathrm{O}\right)$.

$29.2 \pm 0.2 \mu \mathrm{g} / \mathrm{g}$ and $2161 \pm 19 \mu \mathrm{g}$ GAE$/ \mathrm{g}$, respectively, which were close to the predicted values $(31.8 \mu \mathrm{g} / \mathrm{g}$ of total carotenoids and $2370 \mu \mathrm{g}$ GAE/g of total phenolic compounds) with low relative error values $(<10 \%)$.
Regarding the other solvents, the contour plots were generated only to illustrate the observed tendencies for the UAE of carotenoids and phenolic compounds from both orange and yellow peach palm fruits (Figure 3). Considering the maximum and minimum 
contents of both bioactive compounds that could be extracted by each solvent, all the graphs were built to highlight the effects of the number of extraction and solid-liquid ratio, which were the most relevant variables, and they were useful to suggest the best UAE conditions for the simultaneous extraction. As the extraction time presented very low or none influence to the UAE for all the tested solvents, its value was fixed at the lowest value of CCRD ( $2 \mathrm{~min}$ ) to provide a non-time-consuming procedure.

Interestingly, the contour plots for each solvent (Figure 3) suggested that simultaneous extraction of high contents of carotenoids and phenolic compounds can be achieved at the same UAE conditions for both fruit varieties. Therefore, ethanol in combination with UAE technique tends to provide high contents of both compounds after 10 extractions of $2 \mathrm{~min}$ each at a solid-liquid ratio of 1:10 (w/v), while 15 extractions of 2 min each at a solid-liquid ratio of 1:5 (w/v) was the selected conditions when ethyl acetate was used. As expected, for the mixture of ethanol/water, the same optimized UAE conditions found for the orange peach palm fruits were indicated for the yellow peach palm fruits.

\section{Conclusion}

To the best of our knowledge, this is the first report concerning the application of UAE for the simultaneous extraction of carotenoids and phenolic compounds from the pulp of peach palm fruits with solvents with different polarities. Both the orange and yellow peach palm fruits were considered as promising sources of bioactive compounds since they presented high contents of carotenoids and phenolic compounds. During the UAE experiments, the number of extraction and solidliquid ratio were the variables that most affected the bioactive compounds extraction $(\mathrm{p}<0.05)$. However, after the statistical evaluation of the CCRD data by RSM, only the model proposed for ethanol/water $(1: 1, \mathrm{v} / \mathrm{v})$ in the UAE of carotenoids and phenolic compounds from orange peach palm fruits was able to predict the experimental data and the optimal conditions were 10 extractions of 2 min each at a solid-liquid ratio of $1: 12(\mathrm{w} / \mathrm{v})$. Therefore, the UAE proved to be a simple and effective technique to carry out simultaneous extraction of high concentrations of bioactive compounds depending on the solvent, with similar or superior recovery percentage as compared to the obtained by conventional methods.

\section{Acknowledgements}

The authors acknowledge FAPESPA (Fundação Amazônia de Amparo a Estudos e Pesquisas, Belém, PA, Brazil, Project 2017/52864 - ICAAF № 013/2018) for the financial support.

\section{Conflict of interest}

The author declare that they have no conflict of interest.

\section{References}

Azmir, J., Zaidul, I. S. M. M., Rahman, M. M., Sharif, K. M., Mohamed, A., Sahena, F., Jahurul, M. H. A. A., Ghafoor, K., Norulaini, N. A. N. N., \& Omar, A. K. M. M. (2013). Techniques for extraction of bioactive compounds from plant materials: a review. Journal of Food Engineering, 117(4), 426-436. http://dx.doi.org/10.1016/j. jfoodeng.2013.01.014.

Basto, G. J., Carvalho, C. W. P., Soares, A. G., Costa, H. T. G. B., Chávez, D. W. H., Godoy, R. L. O., \& Pacheco, S. (2016). Physicochemical properties and carotenoid content of extruded and non-extruded corn and peach palm (Bactris gasipaes, Kunth). LebensmittelWissenschaft + Technologie, 69, 312-318. http://dx.doi.org/10.1016/j. lwt.2015.12.065.

Box, G. E. P., Hunter, J. S., \& Hunter, W. G. (1978). Statistics for experimenters 623. Hoboken: John Wiley \& Sons. Inc.

Britton, G. (2020). Carotenoid research: history and new perspectives for chemistry in biological systems. Biochimica et Biophysica Acta. Molecular and Cell Biology of Lipids, 1865(11), 158699. http://dx.doi. org/10.1016/j.bbalip.2020.158699. PMid:32205211.

Carrera, C., Ruiz-Rodríguez, A., Palma, M., \& Barroso, C. G. (2012). Ultrasound assisted extraction of phenolic compounds from grapes. Analytica Chimica Acta, 732, 100-104. http://dx.doi.org/10.1016/j. aca.2011.11.032. PMid:22688040.

Carvalho, A. V., Beckman, J. C., Maciel, R. A. E. A., \& Farias, J. T. No. (2013). Physical and chemical characteristics of peach palm fruits in the state of Pará. Revista Brasileira de Fruticultura, 35, 763-768. http://dx.doi.org/10.1590/S0100-29452013000300013.

Chemat, F., Abert-Vian, M., Fabiano-Tixier, A. S., Strube, J., Uhlenbrock, L., Gunjevic, V., \& Cravotto, G. (2019). Green extraction of natural products. Origins, current status, and future challenges. Trends in Analytical Chemistry, 118, 248-263. http://dx.doi.org/10.1016/j. trac.2019.05.037.

Chemat, F., Rombaut, N., Sicaire, A. G., Meullemiestre, A., Fabiano-Tixier, A. S., \& Abert-Vian, M. (2017). Ultrasound assisted extraction of food and natural products. Mechanisms, techniques, combinations, protocols and applications. A review. Ultrasonics Sonochemistry, 34, 540-560. http://dx.doi.org/10.1016/j.ultsonch.2016.06.035. PMid:27773280.

Chisté, R. C., Benassi, M. T., \& Mercadante, A. Z. (2011). Effect of solvent type on the extractability of bioactive compounds, antioxidant capacity and colour properties of natural annatto extracts. International Journal of Food Science \& Technology, 46(9), 1863-1870. http:// dx.doi.org/10.1111/j.1365-2621.2011.02693.x.

Chisté, R. C., Costa, E. L. N., Monteiro, S. F., \& Mercadante, A. Z. (2021). Carotenoid and phenolic compound profiles of cooked pulps of orange and yellow peach palm fruits (Bactris gasipaes) from the Brazilian Amazonia. Journal of Food Composition and Analysis, 99, 103873. http://dx.doi.org/10.1016/j.jfca.2021.103873.

Costa, G. V., Rocha, W. C., \& Freitas, A. D. G. (2019). Endophytic microorganisms found in peach palm fruit (Bactris gasipaes Kunth) and its antimicrobial potential. Scientia Amazonia, 8, 23-27.

Cravotto, G., Boffa, L., Mantegna, S., Perego, P., Avogadro, M., \& Cintas, P. (2008). Improved extraction of vegetable oils under highintensity ultrasound and/or microwaves. Ultrasonics Sonochemistry, 15(5), 898-902. http://dx.doi.org/10.1016/j.ultsonch.2007.10.009. PMid:18093864.

Davies, B. H. (1976). Carotenoids. In T. W. Goodwin (Eds.), Chemistry and biochemistry of plant pigments (pp. 38-165). New York: Academic Press.

European Commission. (1995). Commission Directive 95/45/EC. Laying down specific purity criteria concerning colours for use in foodstuffs. Official Journal of European Community. 
U.S Food and Drug Administration - FDA. (1997). Docket No. 97-D-0148. International conference on harmonisation; guidance on impurities: residual solvents (pp. 67377-67388). Washington: FDA.

Ghitescu, R. E., Volf, I., Carausu, C., Bühlmann, A. M., Gilca, I. A., \& Popa, V. I. (2015). Optimization of ultrasound-assisted extraction of polyphenols from spruce wood bark. Ultrasonics Sonochemistry, 22, 535541. http://dx.doi.org/10.1016/j.ultsonch.2014.07.013. PMid:25132494.

Ordoñez-Santos, L. E., Martínez-Girón, J., \& Rodríguez-Rodríguez, D. X. (2019). Extraction of total carotenoids from peach palm fruit (Bactris gasipaes) peel by means of ultrasound application and vegetable oil. Dyna, 86(209), 91-96. http://dx.doi.org/10.15446/dyna.v86n209.74840.

Hazli, U. H. A. M., Abdul-Aziz, A., Mat-Junit, S., Chee, C. F., \& Kong, K. W. (2019). Solid-liquid extraction of bioactive compounds with antioxidant potential from Alternanthera sesillis (red) and identification of the polyphenols using UHPLC-QqQ-MS/MS. Food Research International, 115, 241-250. http://dx.doi.org/10.1016/j. foodres.2018.08.094. PMid:30599938.

Jatunov, S., Quesada, S., Díaz, C., \& Murillo, E. (2010). Carotenoid composition and antioxidant activity of the raw and boiled fruit mesocarp of six varieties of Bactris gasipaes. Archivos Latinoamericanos de Nutricion, 60(1), 99-104. PMid:21090177.

Luna-Guevara, M. L., Luna-Guevara, J. J., Hernández-Carranza, P., Ruíz-Espinosa, H., \& Ochoa-Velasco, C. E. (2018). Phenolic compounds: a good choice against chronic degenerative diseases. Studies in Natural Products Chemistry, 59, 79-108. http://dx.doi. org/10.1016/B978-0-444-64179-3.00003-7.

Manousi, N., Sarakatsianos, I., \& Samanidou, V. (2019). Extraction techniques of phenolic compounds and other bioactive compounds from medicinal and aromatic plants. In: A. M. Grumezescu \& A. M. Holban (Eds.), Engineering tools in the beverage industry. San Diego: Elsevier Science \& Technology.

Matos, K. A. N., Lima, D. P., Barbosa, A. P. P., Mercadante, A. Z., \& Chisté, R. C. (2019). Peels of tucumã (Astrocaryum vulgare) and peach palm (Bactris gasipaes) are by-products classified as very high carotenoid sources. Food Chemistry, 272, 216-221. http://dx.doi. org/10.1016/j.foodchem.2018.08.053. PMid:30309535.

Moreira, M. M., Morais, S., \& Delerue-Matos, C. (2017). Environment-friendly techniques for extraction of bioactive compounds from fruits, soft chemistry and food fermentation. San Diego: Elsevier Science \& Technology.

Neri-Numa, I. A., Sancho, R. A. S., Pereira, A. P. A., \& Pastore, G. M. (2018). Small Brazilian wild fruits: nutrients, bioactive compounds, health-promotion properties and commercial interest. Food Research International, 103, 345-360. http://dx.doi.org/10.1016/j. foodres.2017.10.053. PMid:29389624.

Ordóñez-Santos, L. E., Pinzón-Zarate, L. X., \& González-salcedo, L. O. (2015). Optimization of ultrasonic-assisted extraction of total carotenoids from peach palm fruit (Bactris gasipaes) by- products with sunflower oil using response surface methodology. Ultrasonics Sonochemistry, 27, 560-566. http://dx.doi.org/10.1016/j. ultsonch.2015.04.010. PMid:25911166.

Rocha, J. C.G., Procópio, F. R., Mendonça, A. C., Vieira, L. M., Perrone, Í. T., Barros, F. A. R., \& Stringheta, P. C. (2017). Optimization of ultrasound-assisted extraction of phenolic compounds from jussara (Euterpe edulis M.) and blueberry (vaccinium myrtillus) fruits. Food Science and Technology, 38(1), 45-53. http://dx.doi. org/10.1590/1678-457x.36316.

Rodriguez-Amaya, D. B. (2019). Update on natural food pigments - a mini-review on carotenoids, anthocyanins, and betalains. Food Research International, 124, 200-205. http://dx.doi.org/10.1016/j. foodres.2018.05.028. PMid:31466641.

Rodriguez-Amaya, D. B. 2001. A guide to carotenoid analysis in foods. Washington: ILSI Press.

Rojas-Garbanzo, C., Pérez, A. M., Bustos-carmona, J., \& Vaillant, F. (2011). Identi fi cation and quanti fi cation of carotenoids by HPLCDAD during the process of peach palm (Bactris gasipaes H. B. K. ) flour. Food Research International, 44(7), 2377-2384. http://dx.doi. org/10.1016/j.foodres.2011.02.045.

Rojas-Garbanzo, C., Pérez, A. M., Castro, M. L. P., \& Vaillant, F. (2012). Major physicochemical and antioxidant changes during peachpalm (Bactris gasipaes H.B.K.) flour processing. Fruits, 67(6), 415-427. http://dx.doi.org/10.1051/fruits/2012035.

Rojas-Garbanzo, C., Pérez, A. M., Vaillant, F., \& Pineda-Castro, M. L. (2016). Physicochemical and antioxidant composition of fresh peach palm (Bactris gasipaes Kunth) fruits in Costa Rica. Brazilian Journal of Food Technology, 19, e2015097. http://dx.doi.org/10.1590/19816723.9715.

Santos, B. W. C., Ferreira, F. M., Souza, V. F., Clement, C. R., \& Rocha, R. B. (2017). Discriminant analysis of the physical and chemical characteristics of peach palm fruits (Bactris gasipaes Kunth) from the upper Rio Madeira, Rondônia, Brasil. Científica, 45, 154-161. http://dx.doi.org/10.15361/1984-5529.2017v45n2p154-161.

Silva, L. R., \& Silva, B. M. 2016. Natural bioactive compounds from fruits and vegetables as health promoters part II. Sharjah: Bentham Science Publishers.

Singleton, V. L., Orthofer, R., \& Lamuela-Raventós, R. M. (1999). Analysis of total phenols and other oxidation substrates and antioxidants by means of folin-ciocalteu reagent. Methods in Enzymology, 299, 152178. http://dx.doi.org/10.1016/S0076-6879(99)99017-1.

Wen, C., Zhang, J., Zhang, H., Dzah, C. S., Zandile, M., Duan, Y., Ma, H., \& Luo, X. (2018). Advances in ultrasound assisted extraction of bioactive compounds from cash crops - a review. Ultrasonics Sonochemistry, 48, 538-549. http://dx.doi.org/10.1016/j. ultsonch.2018.07.018. PMid:30080583. 